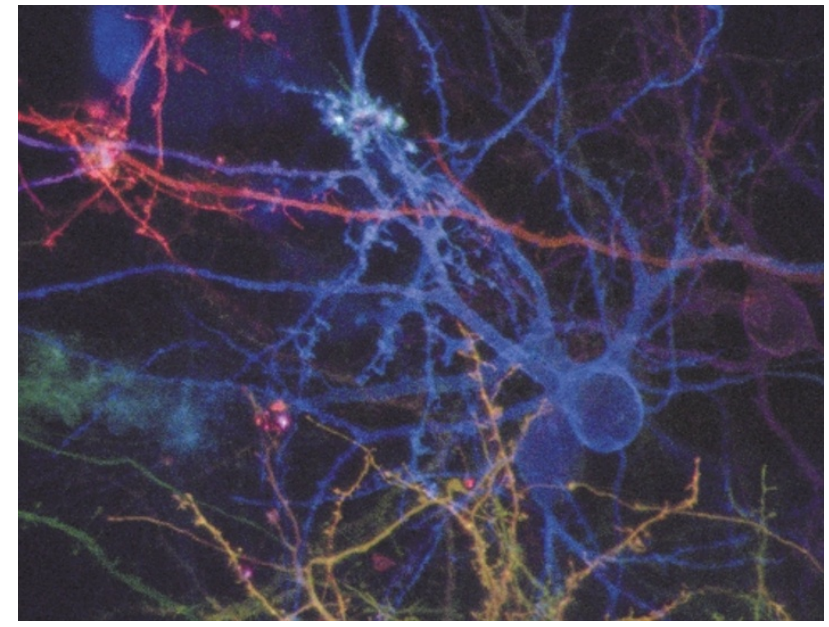

Image courtesy of J. W. Lichtman, Washington University School of Medicine, St Louis, Missouri, USA.

\section{CELLULAR IMAGING}

\section{The future's so bright}

The ability to selectively label tissue has been a great asset for the analysis of the architecture and connectivity of the brain. Although there has been rapid progress in recent years, particularly with the advent of green fluorescent protein (GFP) and similar compounds that can be used to label cells in transgenic animals, these approaches have some limitations. For example, although one can use plasmids encoding the GFP gene to label individual cells in slices or cultures, the expression of the gene (and therefore the labelling of the cell) may take up to six hours after transfection. This delay between transfection and labelling can limit the utility of this approach in some studies. Moreover, the specificity of the gene-gun approach that is used to fire plasmid-coated beads into the tissue can mean that high density labelling is achieved at the expense of tissue damage. One alternative is to use lipophilic, carbocyanine dyes, although it is technically difficult to label individual cells with this technique.

A paper published in the August issue of Neuron by Gan and colleagues describes an ingenious, hybrid approach. Their technique (DiOlistic labelling) also uses particle-mediated ballistic delivery by a gene gun but this time employs lipophilic dyes such as $\mathrm{DiO}$, DiI and $\mathrm{DiD}$ to provide the label. By coating beads with different dye combinations, Gan and colleagues were able to show that living or fixed tissue could be rapidly labelled at high densities. Membrane filters placed between the gene gun and the tissue limited particle clustering and tissue damage. In live tissue, dendritic trees and glial cells appeared to be fully labelled within five minutes of particle contact. One of the exciting aspects of this study was that different neurons could be labelled with different colours either by using individual lipophilic dyes or combinations thereof. So by altering the relative quantities of different dyes up to seven different easily distinguishable colours were visualized, with the possibility of many more. Although this approach does have some limitations in certain situations, the description of the multicolour labelling DiOlistic technique may be a valuable addition to the armoury of the neuroanatomist.

Peter Collins

(0) References and links

ORIGINAL RESEARCH PAPER Gan, W.-B. et al. Multicolor "DiOlistic" labeling of the nervous system using lipophilic dye combinations. Neuron 27, 219-225 (2000).

REVIEW Tsien, R.Y. The green fluorescent protein. Annu. Rev. Biochem. 67, 509-544 (1998). FURTHER READING Chalfie, M. et al. Green fluorescent protein as a marker for gene expression. Science 263, 802-805 (1994).

WEB SITE GFP Applications Page designed by Wallace Marshall, Yale University
H I G H L I G H T S

\title{
Cleavage: resolving a sticky problem
}

Have you ever considered the paradox of how a tightly bound link between two surfaces can be both very secure and reversible? Probably not, I guess. But the people at the Velcro companies did and came up with the idea for 'loop and hook' fasteners that have found so many applications in recent years - so much so that the name of the company has become a ing. A similar, somewhat paradoxical, issue exists in the field of axon guidnisms leading to the precise spatial patterning of neural connections. Here, it is thought that repellent signalling, one of the basic mechanisms of axon guidance, is mediated by direct cell-cell contact. So how does cell adhesion lead to repulsion and how is this mechanism controlled so that repulsion is transient rather than permanent? studies published in Science. In the first study Hattori, Osterfield and Flanagan describe how contactmediated axon repulsion is achieved by an interaction between the metalloprotease Kuzbanian, and both the axon guidance molecule ephrin and the Eph receptors. Ephrin ligands are membrane-bound proteins that bind tightly to their respective tyrosine kinase receptors of the Eph family. The growth cone of an extending process contains Eph receptors that bind to ephrin ligands, located on the surfaces of other cells and this promotes adhesion of the two cells. Hattori and colleagues generic term for this type of fastenance that seeks to uncover the mecha-

An answer is provided by two

showed that ephrin-A2 forms a stable complex with Kuzbanian in the absence of Eph receptors. However, once the ephrin ligand binds to the Eph receptor, Kuzbanian is activated and cleaves ephrin-A2 from the cell surface in a localized reaction. A key experiment showed that a mutation of ephrin-A2 that blocked ephrin cleavage did not prevent growthcone collapse but did delay axon withdrawal.

The importance of metalloproteases in axon guidance was further emphasized by Galko and TessierLavigne. These authors showed that the effects of another guidance molecule - the axonal chemoattractant, netrin-1 - could be potentiated by metalloprotease inhibition. This effect may result from stabilization of the netrin receptor DCC (Deleted in Colorectal Cancer) on the axon.

These two papers show that metalloprotease proteolytic activity is a critical regulator of axon guidance and that, when it comes to finding new solutions to sticky problems, nature often finds an elegant solution.

Peter Collins

(10) Reference and links ORIGINAL RESEARCH PAPERS Hattori, M., Osterfield, M. \& Flanagan, J. G. Regulated cleavage of a contact-mediated axon repellent. Science 289, 1360-1364 (2000). | Galko, M. J. \& Tessier-Lavigne, M. Function of an axonal chemoattractant modulated by metalloprotease activity. Science 289, 1365-1367 (2000). REVIEWS Flanagan, J. G. \& Vanderhaeghen, P. The ephrins and Eph receptors in neural development. Annu. Rev. Neurosci. 21, 309-345 (1998). | Black, R. A. \& White, J. M. ADAMs: focus on the protease domain. Curr. Opin. Cell Biol. 10, 654-659 (1998).

WEB SITES John Flanagan's homepage | Marc Tessier-Lavigne's homepage

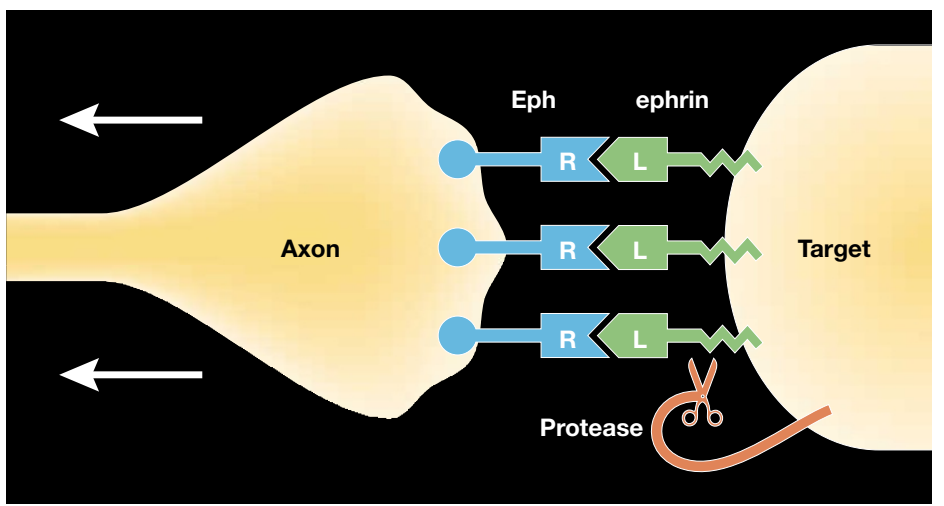

